\title{
A genetic programming predictive model for parametric study on factors affecting strength of geopolymers $\uparrow$
}

\author{
H. Y. Leong ${ }^{1}$; D .E. L. Ong ${ }^{1}$, J. G. Sanjayan ${ }^{2}$ and A. Nazari²,* \\ ${ }^{1}$ Research Centre for Sustainable Technologies, Faculty of Engineering, Science \& Computing, Swinburne \\ University of Technology Sarawak Campus, 93350 Kuching, Sarawak, Malaysia. \\ ${ }^{2}$ Centre for Sustainable Infrastructure, Faculty of Science, Engineering and Technology, Swinburne University \\ of Technology, PO Box 218, Hawthorn Victoria 3122, Australia. \\ * Corresponding author, Email: alinazari@swin.edu.au; Tel: +61 392148370
}

\begin{abstract}
In this paper, the effect of different factors including mixture proportions and curing conditions on compressive strength of fly ash-based geopolymers was studied. Several parameters were used to construct a predictive model based on genetic programming, which deliver the compressive strength of specimens with reasonable accuracy. A parametric study was carried on to evaluate the effect of each individual parameter on strength of geopolymers. The results obtained by the model showed that changing the percentage of aggregates in the standard range and age of curing are ineffective on compressive strength of the considered geopolymer. On the other hand, increasing the percentage of fly ash, curing temperature and liquid to ash weight ratio were shown to assist compressive strength to improve. Another important parameter namely, sodium silicate to alkali hydroxide weight ratio had an optimum value of 2.5 to deliver the highest strength. All of model predictions were in accordance to the experimental results and those available in the literature for many types of fly ashbased geopolymers. It was concluded that Sarawak fly ash can be suitably used to synthesize geopolymers when the producing factors are precisely determined.
\end{abstract}

Keywords: Alkali-activated binders; compressive strength; genetic programming; parametric modelling

\section{Introduction}

Development of sustainable construction materials is of prime importance to ensure environmentally viable future for the world. Emission of greenhouse gases through industrial activities has major impacts on global warming. Global warming is the primary disadvantage as a result of such emission. $\mathrm{CO}_{2}$ forms the major part of greenhouse gases and it is estimated that 5-7 \% of $\mathrm{CO}_{2}$ emission is due to production of concrete [1]-[2]. Alkali-activated binders (geopolymers) as eco-friendly construction materials with much lower $\mathrm{CO}_{2}$ footprint 
are considered as one of the possible substitutions for ordinary Portland cement (OPC) [3]-[5]. Because fly ash is abundantly available in the world (for instance, Australia produces 14 million tons per annum with only 2 to 3 million tons being used), it is currently the most attractive raw construction material for production of geopolymer concrete. Fly ash-based geopolymers are produced by mixing fly ash (as aluminosilicate source) and a regular silica-rich alkali activator (normally a combination of sodium or potassium silicate, and sodium or potassium hydroxide) [6].

Fly ash is a by-product from combustion of coal which contains fine particles arisen from flue gases. Those particles that are not come with flue gases are called bottom ash. Depending on the source and makeup of the coal being burned, the components of fly ash vary considerably, but all fly ash includes substantial amounts of $\mathrm{SiO}_{2}$ (both amorphous and crystalline) and $\mathrm{CaO}$. Fly ash is classified to class $\mathrm{F}$ and class $\mathrm{C}$ fly ash according to their $\mathrm{CaO}$ content [6]. While class $\mathrm{F}$ fly ash has low contents of $\mathrm{CaO}$, class $\mathrm{C}$ fly ash normally contains more than 20 wt.\% CaO. Calcium-(Sodium)-Aluminosilicate-hydrate [C-(N)-A-S-H] and Sodium-Aluminosilicatehydrate (N-A-S-H) are the most possible amorphous gels formed during geopolymerization of class $\mathrm{C}$ and class F fly ash respectively [7]. Geopolymer concrete made from both types of fly ash may have compressive strength values ranging from medium to high strength [8]-[10]. Fly ash is naturally low reactive material and in most cases, fly ash-based geopolymers are produced by oven curing. Oven-cured geopolymers gain their maximum strength at early ages [6],[11].

Variability in chemical composition of fly ash is the major problem which requires careful attention to provide sustainable specimens. Scattered results are reported on the effect of different production variables on the final geopolymer. Specific types of fly ash have now been characterized to achieve reproducible results through standard procedures. For example, Gladstone fly ash is recognized as the best quality fly ash of Australia to produce geopolymer [12]. Although there are other types of fly ash such as Collie, Eraring and Tarong in Australia, they are unable to be synthesized appropriately to deliver a reliable geopolymer product [12]-[14]. This is more or less the case construction material researcher around the world face with. In Sarawak, Malaysia, Sejingkat and Mukah Power Stations are estimated to produce about 1,400 tonnes of fly ash per day due to coal-firing (fly ash is sourced from Sejingkat Power Station for this paper). About $99 \%$ of the produced fly ash is captured by the electrostatic precipitator and solely few amounts are discharged to the environment. Preliminary examinations revealed the potential of Sarawak fly ash (SFA) for geopolymer making. However, indepth examinations are required to evaluate the effect of various parameters on the performance of final geopolymeric product. In this paper, a model based on genetic programming is proposed for parametric study of 
factors influencing compressive strength of geopolymers made by SFA.

Genetic programming (GP), an extension to genetic algorithm proposed by Koza [15], is recently used in many civil engineering applications [16]-[19]. It is an evolutionary algorithm-based methodology inspired by biological evolution to solve the task of relating independent input parameter to an output parameter through linear or nonlinear equations. Similar to all evolutionary algorithms, mutation and crossover are the main operators used. A detailed overview on the GP concept is accessible through Ref. [15]. Many factors can influence the compressive strength of a geopolymer concrete specimen. Among them, percentage of fly ash, percentage of sand, percentage of $\mathrm{Na}_{2} \mathrm{SiO}_{3}$, curing temperature, age of curing, $\mathrm{Na}_{2} \mathrm{SiO}_{3}$ to $\mathrm{NaOH}(\mathrm{KOH})$ weight ratio and liquid to ash weight ratio are selected in this paper and a relationship is established between these input parameters and the corresponding compressive strength values (output parameter). Furthermore, a parametric analysis is conducted to evaluate the effect of each individual input parameter on the compressive strength. The parametric study can effectively predict the variations of mixture proportions and curing condition, as a general trend, on final strength of the considered geopolymer concrete specimens.

\section{Experimental Procedure to collect the data}

SFA used contained $43.8 \% \mathrm{SiO}_{2}, 18.1 \% \mathrm{Al}_{2} \mathrm{O}_{3}, 7.7 \% \mathrm{Fe}_{2} \mathrm{O}_{3}, 3.9 \% \mathrm{CaO}, 0.5 \% \mathrm{MgO}, 22.8 \% \mathrm{MnO}$, $2.0 \% \mathrm{~K}_{2} \mathrm{O}, 0.3 \% \mathrm{Na}_{2} \mathrm{O}, 0.1 \% \mathrm{SO}_{3}, 0.6 \% \mathrm{TiO}_{2}, 0.1 \% \mathrm{P}_{2} \mathrm{O}_{5}$ with los on ignition (L.O.I) of 0.5. SFA was dry mixed by sand with the sand:SAF weight ratio of 2:1. Alkali activator was a combination of industrial grade sodium silicate and $8 \mathrm{M}$ sodium hydroxide $(\mathrm{NaOH})$ or potassium hydroxide $(\mathrm{KOH})$. Different ratios of alkali activator to ash $(0.3,0.4,0.5$ and 0.6$)$ and $\mathrm{Na}_{2} \mathrm{SiO}_{3} / \mathrm{NaOH}$ or $\mathrm{Na}_{2} \mathrm{SiO}_{3} / \mathrm{KOH}(0.5,1,1.5,2,2.5$ and 3$)$ were examined. Specimens were cured at 25 or $60{ }^{\circ} \mathrm{C}$ for 1 or 7 days. Weight percentages of $\mathrm{Na}_{2} \mathrm{SiO}_{3}$ ranged between 3.0 and 12.5. In total, 144 mixtures were produced and tested to be used in modelling procedure. The mixtures were casted into the cubic moulds with dimensions of $50 \mathrm{~mm} \times 50 \mathrm{~mm} \times 50 \mathrm{~mm}$ and compressive strength values achieved through testing of the produced samples in accordance to the ASTM C109 standard [20]. Input parameters were arranged in the form of seven independent factors including percentage of fly ash, percentage of sand, percentage of $\mathrm{Na}_{2} \mathrm{SiO}_{3}$, curing temperature, age of curing, $\mathrm{Na}_{2} \mathrm{SiO}_{3}$ to $\mathrm{NaOH}(\mathrm{KOH})$ weight ratio and liquid to ash weight ratio. Compressive strength of samples was considered as the output parameter. Table 1 shows some statistical parameters and Fig. 1 presents cumulative frequency distribution of all input and target parameters. Mixture proportions, curing condition, compressive strength and standard deviation of these 144 
data are given in ESI†.

\section{Modelling by genetic programming}

\subsection{Modelling Procedure}

GeneXProtools 4 software was used in this paper to acquire relationship between the compressive strength values and input parameters. In GP, the task of linking of input parameters is followed by various functions. In this paper, four basic operators $(+,-, \times, /)$ and some other functions including $x^{2}, x^{3}, \sqrt{ }, \sqrt[3]{ }, \exp$ and $l n$ were used. A GP-based model is constructed by expression trees (ETs) where equations are derived from these ETs. An ET contains several genes (sub-ETs) where each of them contains some chromosomes. Each chromosome may contains whether one of input parameters or functions. Some constants are used by the model to adjust the equations. Fig. 2 illustrates ET acquired for the model of this paper. In this figure, d0, d1, d2, d3, d4, d5 and d6 represents percentage of fly ash $(F)$, percentage of sand $(S)$, percentage of $\mathrm{Na}_{2} \mathrm{SiO}_{3}(N)$, curing temperature $(T)$, age of curing $(t), \mathrm{Na}_{2} \mathrm{SiO}_{3}$ to $\mathrm{NaOH}(\mathrm{KOH})$ weight ratio $(H)$ and liquid to ash weight ratio $(L)$. The exact value of c0 in sub-ET 1 is 8.843842 , c1 in sub-ET 1 is 3.579254 , and c0 in sub-ET 3 is -8.576813 . The final simplified equation shows compressive strength $\left(f_{s}\right)$ of geopolymer mixtures.

Number of sub-ETs and chromosomes are two of the most important parameters which have direct impact on complexity and accuracy of a model. Limited number of sub-ETs/chromosomes could result in low accuracies and large number of them could cause a complex inefficient equation which sometimes has only a little more accuracy. There should be an optimum number of these parameters for any specific problem. Unfortunately, there is not a standard way to determine the optimum number of sub-ETs or chromosomes. The most acceptable way is to use one sub-ET with some number of chromosomes and then, run the model and monitor the results. Number of sub-ETs and chromosomes are increased hereafter, to attain the desirable accuracy. In this paper, a reliable equation was achieved by using three sub-ETs and maximum of 12 chromosomes for each sub-ET. The program might use less number of chromosomes that the maximum allowed according to the accuracy it reaches. In this paper, as Fig. 2 shows, 11 chromosomes for all sub-ETs are used.

Head size is another important parameter which determines the number of branches of each sub-ET (i.e., the number of chromosomes which their bottom has not linked to other chromosomes). In this paper, maximum number of head size of 6 was defined and the model used 5. Finally, it is important to link the ETs through a linking function. The task of choosing linking function is not obey a standard procedure and in this paper was followed by selecting a function and monitoring the results. Virtually, one of four basic operators is 
used and in this paper, multiplication is used as liking function. Other parameters used to construct the model are listed in Table 2.

A total number of 144 datasets were collected from the experiments and divided into 100, 22 and 22 series and were used for training, testing and validating the results. Validating is followed to realize whether the accuracy of the model from new source is acceptable. Modelling was continued until coefficient of determination $\left(R^{2}\right)$ of more than 0.9 was acquired for all training, testing and validating phases. Although it was possible to achieve higher accuracies, the model could not be attainable through a simple practical equation and hence, the one described in the next section was selected. It is very important to have a model trained, tested and validated with approximately same accuracies in all of these three phases which we acquired in this paper.

\subsection{Modelling results}

The equation obtained by the model through simplifying Fig. 2 can be represented as follows:

$f_{S}=\ln ((F-N-8.84) \cdot \ln (3.58 L)) \cdot((H . T-t) \ln (S . T))^{\frac{1}{3}} \cdot \ln \left(\left(-8.58+H+\frac{L}{t}\right) \ln L\right)$

The accuracy of the model was evaluated through monitoring $R^{2}$, mean absolute error (MAE), root mean square error $(R M S E)$, relative absolute error $(R A E)$ and root relative square error (RRSE) values achievable by the following formulations [21]:

$$
\begin{gathered}
R^{2}=1-\left(\frac{\sum_{i}\left(t_{i}-o_{i}\right)^{2}}{\sum_{i}\left(o_{i}\right)^{2}}\right) \\
M A E=\frac{1}{n} \sum_{i}\left|t_{i}-o_{i}\right| \\
R M S E=\sqrt{\frac{1}{n} \sum_{i}\left(t_{i}-o_{i}\right)^{2}} \\
R A E=\frac{\sum_{i}\left|t_{i}-o_{i}\right|}{\sum_{i}\left|t_{i}-\frac{1}{n} \sum_{i} t_{i}\right|} \\
R R S E=\sqrt{\frac{\sum_{i}\left(t_{i}-o_{i}\right)^{2}}{\sum_{i}\left(t_{i}-\frac{1}{n} \sum_{i} t_{i}\right)^{2}}}
\end{gathered}
$$

where $t_{i}$ is the target parameter, $o_{i}$ is the output parameter and $n$ is the number of datasets.

Values of $R^{2}, M A E, R M S E, R A E$ and $R R S E$ for training, testing and validating phase of the model are tabulated in Table 3. Maximum and minimum values of $R^{2}$ are 0.9209 and 0.9039 in training and validating phases respectively. Maximum amount of all errors are relevant to validating phase. Regardless of $R A E$, minimum amount of errors is relevant to training phase. For training, testing and validating phases, $R^{2}$ values are 
very close together; this is the case for specific errors values. This may indicate that the model has been trained well and the results can be used with confidence.

Fig. 3 shows predicted vs. experimental compressive strength of geopolymers in all training, testing and validating phases. The figure shows that in all phases, a reasonable distribution of data from lower to upper band of compressive strength data have been used. Table 4 shows the testing datasets together with predicted compressive strength values of geopolymers. Fig. 4 presents residuals arisen during modelling of compressive strength of geopolymer in all training, testing and validating phases. Table 4 and Fig. 4 indicate that the model predicts the values well and in most cases, the residuals are negligible. On the whole, the presented model can be used as an accurate predictable approach to evaluate performance of geopolymer mixes using SFA.

\section{Parametric study of the effect of different parameters on strength of geopolymers}

In this section, a parametric study is developed to evaluate the effect of each parameter on compressive strength of geopolymers using SFA. Parametric study can be considered as an accurate way to determine the importance of each input parameter on output parameter. In this approach, the effect of a specific input parameter on the output parameter is considered when the other input parameters are kept constant. The amount of this constant may be important. In this paper, we used average values of each parameter in accordance to Table 1. This type of parametric study only shows the effect of one input on the target parameter. To include the effect of other input parameters on this parametric analysis, another approach was followed. For example, Fig. 5 shows the effect of variations of the percentage of sand on compressive strength values whereas the effect of other input parameters on this curve is presented. To study this effect, minimum and maximum values of a specific parameter (for example fly ash with minimum and maximum percentage of 27.8 and 30.3 respectively) in accordance to Table 1 are used.

\subsection{Effect of aggregates (sands)}

Fig. 5 illustrates the effect of sands on compressive strength of geopolymers where the other input parameters are constant. In this figure, the effect of changing other input parameters from their minimum to maximum values is considered as well. As it is seen, compressive strength of geopolymer made by SFA is independent of the percentage of sand and is the same for a specific mixture. Although it is well-known that the strength of a concrete primarily depends on the amount of aggregates, the results here could be acceptable. Due to the design limitations, we used a very narrow range of sand percentage and hence, the results may not be 
much different; this might show the accuracy of the parametric study. Figs. 5a and 5c show that the effect of changing percentage of fly ash and age of curing from their minimum to maximum values is negligible. Fig. 5b shows the effect of curing temperature on strength of geopolymer mixtures. As only two different temperatures $\left(25\right.$ and $60^{\circ} \mathrm{C}$ ) have been studied in this paper, it is obvious that increasing of the temperature has positive effect on improvement of compressive strength. Fly ash is a low reactive material and furnace curing of fly ash-based geopolymers is necessary to facilitate geopolymerization to attain higher strengths faster. Fig. 5d shows that increasing the amount of sodium silicate to sodium silicate/ $\mathrm{NaOH}(\mathrm{KOH})$ has positive effect on improvement of compressive strength values. This is in accordance to some evidences which show increasing of the strength of geopolymers by increasing the amount of this ratio in presence of low and medium concentrations of $\mathrm{NaOH}$ (same as this paper) [22],[23]. However, there should be a balance between the amount of sodium silicate and alkali hydroxide $(\mathrm{NaOH}$ or $\mathrm{KOH})$ to have the highest strength. Additional amounts of sodium silicate may remain in the system and just act as a glue. Furthermore, extra sodium silicate is readily react with $\mathrm{CO}_{2}$ and produced compounds with low strength. Fig. 5e shows the positive effect of increasing of liquid (sodium silicate $+\mathrm{NaOH}(\mathrm{KOH}))$ on compressive strength. This effect is same as the effect of sodium silicate/ $\mathrm{NaOH}(\mathrm{KOH})$ on compressive strength and more strength is attainable by dissolving of more silica and alumina in presence of higher amounts of liquid to ash ratio.

\subsection{Effect of fly ash}

Fig. 6 illustrates the effect of variations in percentage of fly ash on compressive strength of geopolymers. A slight increment in compressive strength is observed when the percentage of fly ash in the mixture rises. The effect of fly ash can be considered similar to OPC in concrete where higher amounts of OPC cause improvement in strength. One may consider the effect of liquid to ash ratio in Fig. $6 \mathrm{~d}$ and discuss that higher amount of liquid caused higher strength contradicting the general overview of Fig. 6. It should be noted that percentage of fly ash and liquid to ash weight ratios are independent input parameters and higher amount of one does not necessarily indicate the lower amount of the other. For example, as Table 4 shows, percentage of fly ash and sodium silicate for Sample 1 are 28.6 and 4.8 respectively. For Sample 3, both weight ratios have increased to 29.4 and 7.8 respectively. This example may show the independency of these input parameters. Fig. 5 shows again that by increasing the value of other input parameters, compressive strength values improve which is in accordance to the results obtained in Fig. 5. 


\subsection{Effect of curing temperature and age}

Fig. 7 shows the effect of curing temperature on compressive strength of geopolymers. As mentioned before, fly ash is a low reactive aluminosilicate source which their resultant geopolymers require oven curing to achieve higher strengths faster. The effect of sodium silicate/ $\mathrm{NaOH}(\mathrm{KOH})$ and liquid/ash weight ratios are similar to those discussed earlier in this paper. Fig. $7 \mathrm{~b}$ shows that age of curing has approximately no effect on compressive strength of geopolymers. This is obvious from Fig. 8 as well. As mentioned before, age of curing may be unimportant for oven-cured geopolymers where they attain their strength at initial hours of oven curing.

\subsection{Effect of sodium silicate to alkali hydroxide $(\mathrm{NaOH}$ or $\mathrm{KOH})$ weight ratio}

Fig. 9 shows the effect of sodium silicate/ $\mathrm{NaOH}(\mathrm{KOH})$ weight ratio on compressive strength of geopolymers. The strength reaches to its maximum value at ratio of 2.5 . This is in accordance to many available literatures which confirm that there should be an optimum ratio to have the highest strength [22],[23]. It is very important to have a balance between sodium silicate and alkali hydroxide $(\mathrm{NaOH}$ or $\mathrm{KOH})$. Where the higher amount of sodium silicate is important to provide additional amorphous silica for geopolymerization, presence of $\mathrm{Na}^{+}$and $\mathrm{K}^{+}$is essential to balance the charges and make aluminosilicate network Moreover, higher amount of $\mathrm{NaOH}$ or $\mathrm{KOH}$ dissolves more $\mathrm{Si}^{4+}$ and $\mathrm{Al}^{3+}$ and cause higher strength geopolymer [23]. Additional amounts of any of sodium silicate or alkali hydroxide may change the balance of a system. Therefore, it is very important to achieve the optimum ratio to have the highest strength.

\section{Conclusions}

In this paper, a predictive model based on genetic programming was presented to correlate compressive strength of SFA-based geopolymers to seven factors including percentage of fly ash, percentage of sand, percentage of $\mathrm{Na}_{2} \mathrm{SiO}_{3}$, curing temperature, age of curing, $\mathrm{Na}_{2} \mathrm{SiO}_{3}$ to $\mathrm{NaOH}(\mathrm{KOH})$ weight ratio and liquid to ash weight ratio. The best model was acquired through using 3 sub-ETs, 11 chromosomes for each sub-ET, 5 head size for each sub-ET and multiplication as the linking function of sub-ETs. Accuracy of the model was evaluated through $R^{2}$ and some of error values. A parametric analysis conducted to evaluate the effect of each individual factor on compressive strength of geopolymers. The following conclusion remarks were arisen from this study: 
- $\quad$ SFA can be used to produce geopolymer concrete specimens to achieve reasonable strength. Similar to other concrete mixtures, successful synthesis of geopolymers depends on mixture proportions and curing conditions.

- $\quad$ Genetic programming can be suitably used to predict compressive strength of SFA-based geopolymers. Accuracy of more than $90 \%$ was achieved in training, testing and validating phases of the predictive model, which had reasonable amounts of MAE, RMSE, RAE and RRSE.

- $\quad$ Parametric analysis showed that variation in percentage of sands in the range studied in this paper has unimportant effect on compressive strength. Variation of other factor namely, age of curing was unimportant as well because oven-cured SFA-based geopolymers gain their strength at early ages.

- $\quad$ Increasing the percentage of SFA, curing temperature and liquid to ash weight ratio caused improvement of compressive strength. Higher amounts of SFA acts as OPC in concrete and the other two factors have similar effects to those found in the literature.

- Sodium silicate to $\mathrm{NaOH}$ or $\mathrm{KOH}$ weight ratio showed an optimum value of 2.5 to obtain the highest compressive strength. It was concluded that a balanced ratio is required to achieve the best geopolymerized network.

- $\quad$ The results obtained by the parametric analysis were in accordance to experimental results and those available in the literature for other sources of fly ash.

\section{References}

[1] McLellan, B. C., Williams, R. P., Lay, J., Van Riessen, A., \& Corder, G. D. (2011). Costs and carbon emissions for geopolymer pastes in comparison to ordinary Portland cement. Journal of Cleaner Production, 19(9), 1080-1090.

[2] Nazari, A., \& Sanjayan, J. G. (2015). Synthesis of geopolymer from industrial wastes. Journal of Cleaner Production, 99, 297-304.

[3] Mellado, A., Catalán, C., Bouzón, N., Borrachero, M. V., Monzó, J. M., \& Payá, J. (2014). Carbon footprint of geopolymeric mortar: study of the contribution of the alkaline activating solution and assessment of an alternative route. RSC Advances, 4(45), 23846-23852.

[4] Habert, G., De Lacaillerie, J. D. E., \& Roussel, N. (2011). An environmental evaluation of geopolymer based concrete production: reviewing current research trends. Journal of Cleaner Production, 19(11), 1229-1238. 
[5] Hardjito, D., Wallah, S. E., Sumajouw, D. M., \& Rangan, B. V. (2004). On the development of fly ashbased geopolymer concrete. ACI materials journal,101(6).

[6] Ryu, G. S., Lee, Y. B., Koh, K. T., \& Chung, Y. S. (2013). The mechanical properties of fly ash-based geopolymer concrete with alkaline activators. Construction and Building Materials, 47, 409-418.

[7] Chindaprasirt, P., De Silva, P., Sagoe-Crentsil, K., \& Hanjitsuwan, S. (2012). Effect of SiO2 and Al2O3 on the setting and hardening of high calcium fly ash-based geopolymer systems. Journal of Materials Science, 47(12), 4876-4883.

[8] Fillenwarth, B. A., \& Sastry, S. M. (2015). Development of a predictive optimization model for the compressive strength of sodium activated fly ash based geopolymer pastes. Fuel, 147, 141-146.

[9] Gunasekara, C., Law, D. W., Setunge, S., \& Sanjayan, J. G. (2015). Zeta potential, gel formation and compressive strength of low calcium fly ash geopolymers. Construction and Building Materials, 95, 592599.

[10] Adak, D., Sarkar, M., \& Mandal, S. (2014). Effect of nano-silica on strength and durability of fly ash based geopolymer mortar. Construction and Building Materials, 70, 453-459.

[11]Rickard, W. D., Williams, R., Temuujin, J., \& van Riessen, A. (2011). Assessing the suitability of three Australian fly ashes as an aluminosilicate source for geopolymers in high temperature applications. Materials Science and Engineering: A, 528(9), 3390-3397.

[12] Tennakoon, C., Nazari, A., Sanjayan, J. G., \& Sagoe-Crentsil, K. (2014). Distribution of oxides in fly ash controls strength evolution of geopolymers. Construction and Building Materials, 71, 72-82.

[13] Temuujin, J., Rickard, W., \& Van Riessen, A. (2013). Characterization of various fly ashes for preparation of geopolymers with advanced applications. Advanced Powder Technology, 24(2), 495-498.

[14] Van Riessen, A., \& Chen-Tan, N. (2013). Beneficiation of Collie fly ash for synthesis of geopolymer: Part 1-Beneficiation. Fuel, 106, 569-575.

[15] Koza, J. R. (1992). Genetic programming: on the programming of computers by means of natural selection (Vol. 1). MIT press.

[16] Sarıdemir, M. (2014). Effect of specimen size and shape on compressive strength of concrete containing fly ash: Application of genetic programming for design. Materials \& Design, 56, 297-304.

[17] Cladera, A., Pérez-Ordóñez, J. L., \& Martínez-Abella, F. (2014). Shear strength of RC beams. Precision, accuracy, safety and simplicity using genetic programming. Computers and Concrete, 14(4), 479-501.

[18] Garg, A., Garg, A., \& Tai, K. (2014). A multi-gene genetic programming model for estimating stress- 
dependent soil water retention curves. Computational Geosciences, 18(1), 45-56.

[19] Garg, A., Garg, A., Tai, K., \& Sreedeep, S. (2014). An integrated SRM-multi-gene genetic programming approach for prediction of factor of safety of 3-D soil nailed slopes. Engineering Applications of Artificial Intelligence, 30, 30-40.

[20] ASTM C109 / C109M-13 (2013), Standard Test Method for Compressive Strength of Hydraulic Cement Mortars (Using 2-in. or [50-mm] Cube Specimens), ASTM International, West Conshohocken, PA.

[21] Nazari, A., Rajeev, P., \& Sanjayan, J. G. (2015). Modelling of upheaval buckling of offshore pipeline buried in clay soil using genetic programming.Engineering Structures, 101, 306-317.

[22] Sathonsaowaphak, A., Chindaprasirt, P., \& Pimraksa, K. (2009). Workability and strength of lignite bottom ash geopolymer mortar. Journal of Hazardous Materials, 168(1), 44-50.

[23] Rattanasak, U., \& Chindaprasirt, P. (2009). Influence of $\mathrm{NaOH}$ solution on the synthesis of fly ash geopolymer. Minerals Engineering, 22(12), 1073-1078. 
Table 1. Statistical values for all input and target parameters

\begin{tabular}{|c|c|c|c|c|c|c|c|c|}
\hline Statistical parameter & $\mathrm{F}(\mathrm{wt} \%)$ & $\mathrm{S}(\mathrm{wt} \%)$ & $\mathrm{N}(\mathrm{wt} \%)$ & $\mathrm{T}\left({ }^{\circ} \mathrm{C}\right)$ & $\mathrm{t}$ (days) & $\mathrm{H}$ (weight ratio) & L (weight ratio) & $f_{s}(\mathrm{MPa})$ \\
\hline Minimum & 27.8 & 55.6 & 3.0 & 25 & 1 & 0.5 & 0.3 & 0.2 \\
\hline Maximum & 30.3 & 60.6 & 12.5 & 60 & 7 & 3.0 & 0.6 & 32.7 \\
\hline Range & 2.5 & 5.1 & 9.5 & 35 & 6 & 2.5 & 0.3 & 32.5 \\
\hline Average & 29.0 & 58.0 & 7.7 & 48 & 5 & 1.8 & 0.5 & 16.2 \\
\hline Standard Deviation & 0.9 & 1.9 & 2.5 & 17 & 3 & 0.9 & 0.1 & 9.5 \\
\hline Sample variance & 0.9 & 3.6 & 6.4 & 274 & 8 & 0.7 & 0.0 & 90.5 \\
\hline Median & 29.0 & 58.0 & 7.5 & 60 & 7 & 1.8 & 0.5 & 18.0 \\
\hline Skewness & 0.1 & 0.1 & 0.1 & -1 & -1 & 0.0 & 0.0 & -0.4 \\
\hline Kurtosis & -1.4 & -1.4 & -0.9 & -2 & -2 & -1.3 & -1.4 & -1.1 \\
\hline
\end{tabular}


Table 2. Parameters and characteristics of the model

\begin{tabular}{ll}
\hline Parameter & Value \\
\hline Number of Genes (Sub ETs) & 3 \\
Linking function & 7 \\
Number of variables used & 12 \\
Chromosomes & 6 \\
Head size & 10 \\
Lower bound & -10 \\
Upper bound & 0.044 \\
Mutation & RRSE \\
Fitness function & 0.1 \\
Inversion & 0.1 \\
Transposition & 1 \\
Constants per gene & \\
\hline
\end{tabular}

Table 3. $R^{2}$ and errors of training, testing and validating of the model

\begin{tabular}{llllll}
\hline Phase & $R^{2}$ & $M A E$ & $R M S E$ & $R A E$ & RRSE \\
\hline Training & 0.9209 & 2.0192 & 2.5891 & 0.2616 & 0.2816 \\
Testing & 0.9193 & 2.3741 & 3.0627 & 0.2564 & 0.2883 \\
Validating & 0.9039 & 2.8562 & 4.0021 & 0.2856 & 0.2932 \\
\hline
\end{tabular}


Table 4. Testing datasets together with predicted compressive strength values

\begin{tabular}{|c|c|c|c|c|c|c|c|c|c|}
\hline Sample & $\mathrm{F}(\mathrm{wt} \%)$ & $\mathrm{S}(\mathrm{wt} \%)$ & $\mathrm{N}(\mathrm{wt} \%)$ & $\mathrm{T}\left({ }^{\circ} \mathrm{C}\right)$ & $\mathrm{t}$ (days) & $\mathrm{H}$ (weight ratio) & L (weight ratio) & Experimental $f_{s}(\mathrm{MPa})$ & Predicted $f_{s}(\mathrm{MPa})$ \\
\hline 1 & 28.6 & 57.1 & 4.8 & 60 & 1 & 0.5 & 0.5 & 15.9 & 22.2 \\
\hline 2 & 30.3 & 60.6 & 5.5 & 60 & 1 & 1.5 & 0.3 & 3.11 & 2.46 \\
\hline 3 & 29.4 & 58.8 & 7.8 & 60 & 1 & 2.0 & 0.4 & 30.7 & 26.1 \\
\hline 4 & 30.3 & 60.6 & 6.5 & 60 & 1 & 2.5 & 0.3 & 1.77 & 1.31 \\
\hline 5 & 29.4 & 58.8 & 8.8 & 60 & 1 & 3.0 & 0.4 & 25.1 & 25.4 \\
\hline 6 & 29.4 & 58.8 & 3.9 & 60 & 7 & 0.5 & 0.4 & 20.9 & 20.4 \\
\hline 7 & 30.3 & 60.6 & 4.5 & 60 & 7 & 1.0 & 0.3 & 6.14 & 3.10 \\
\hline 8 & 29.4 & 58.8 & 7.1 & 60 & 7 & 1.5 & 0.4 & 32.5 & 25.8 \\
\hline 9 & 30.3 & 60.6 & 6.1 & 60 & 7 & 2.0 & 0.3 & 2.96 & 1.84 \\
\hline 10 & 29.4 & 58.8 & 8.8 & 60 & 7 & 3.0 & 0.4 & 27.5 & 26.2 \\
\hline 11 & 30.3 & 60.6 & 4.5 & 25 & 7 & 1.0 & 0.3 & 1.39 & 2.08 \\
\hline 12 & 27.8 & 55.6 & 10 & 25 & 7 & 1.5 & 0.6 & 14.1 & 14.8 \\
\hline 13 & 28.6 & 57.1 & 4.8 & 60 & 1 & 0.5 & 0.5 & 15.9 & 22.2 \\
\hline 14 & 29.4 & 58.8 & 7.1 & 60 & 1 & 1.5 & 0.4 & 28.8 & 25.7 \\
\hline 15 & 30.3 & 60.6 & 6.5 & 60 & 1 & 2.5 & 0.3 & 0.38 & 1.31 \\
\hline 16 & 30.3 & 60.6 & 3.0 & 60 & 7 & 0.5 & 0.3 & 1.79 & 3.53 \\
\hline 17 & 27.8 & 55.6 & 8.3 & 60 & 7 & 1.0 & 0.6 & 23.7 & 21.2 \\
\hline 18 & 29.4 & 58.8 & 7.8 & 60 & 7 & 2.0 & 0.4 & 29.0 & 26.4 \\
\hline 19 & 28.6 & 57.1 & 4.8 & 25 & 7 & 0.5 & 0.5 & 10.4 & 12.7 \\
\hline 20 & 27.8 & 55.6 & 8.3 & 25 & 7 & 1.0 & 0.6 & 11.5 & 14.2 \\
\hline 21 & 29.4 & 58.8 & 7.8 & 25 & 7 & 2.0 & 0.4 & 17.4 & 18.4 \\
\hline 22 & 27.8 & 55.6 & 12.5 & 25 & 7 & 3.0 & 0.6 & 10.0 & 13.0 \\
\hline
\end{tabular}




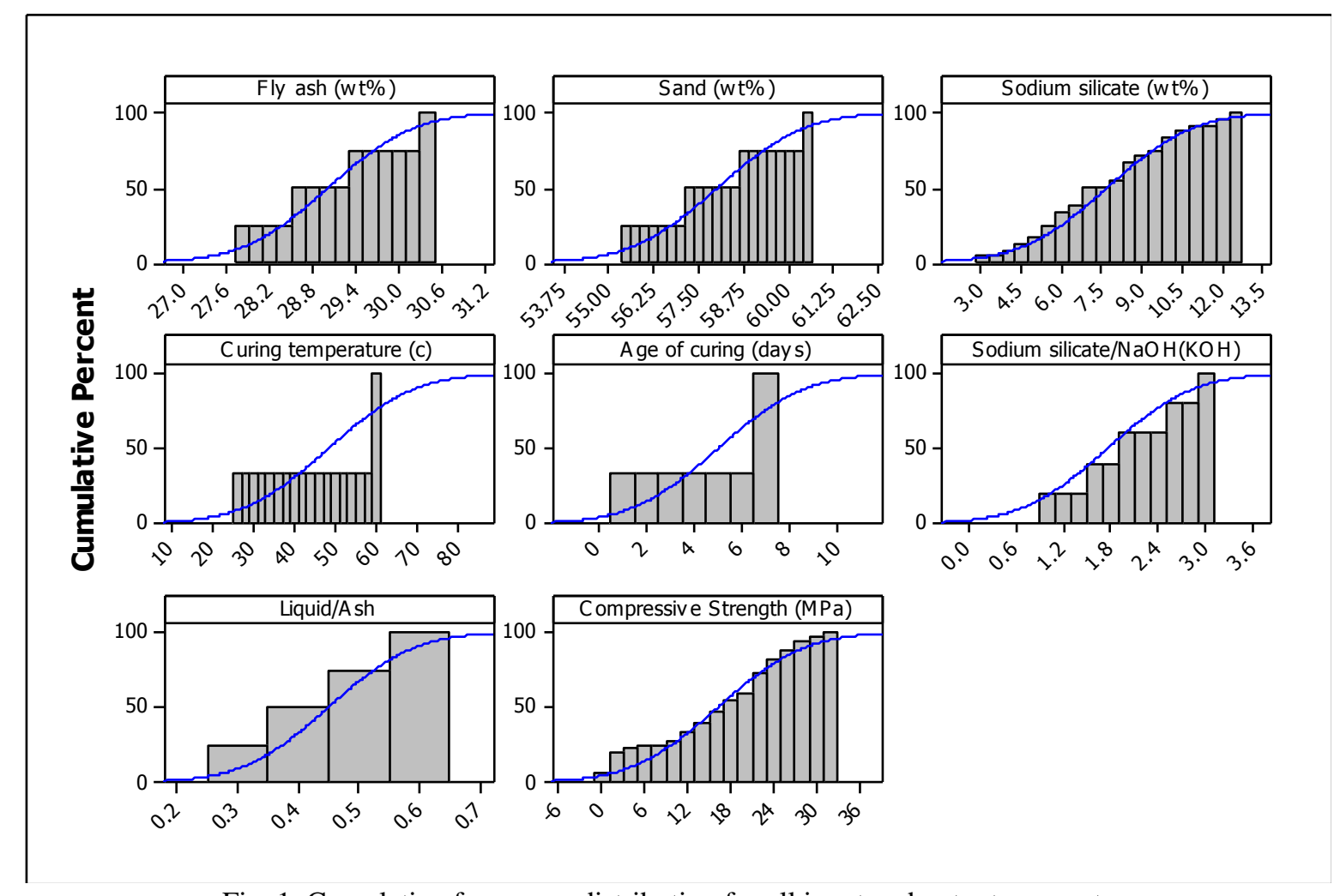

Fig. 1. Cumulative frequency distribution for all input and output parameters 

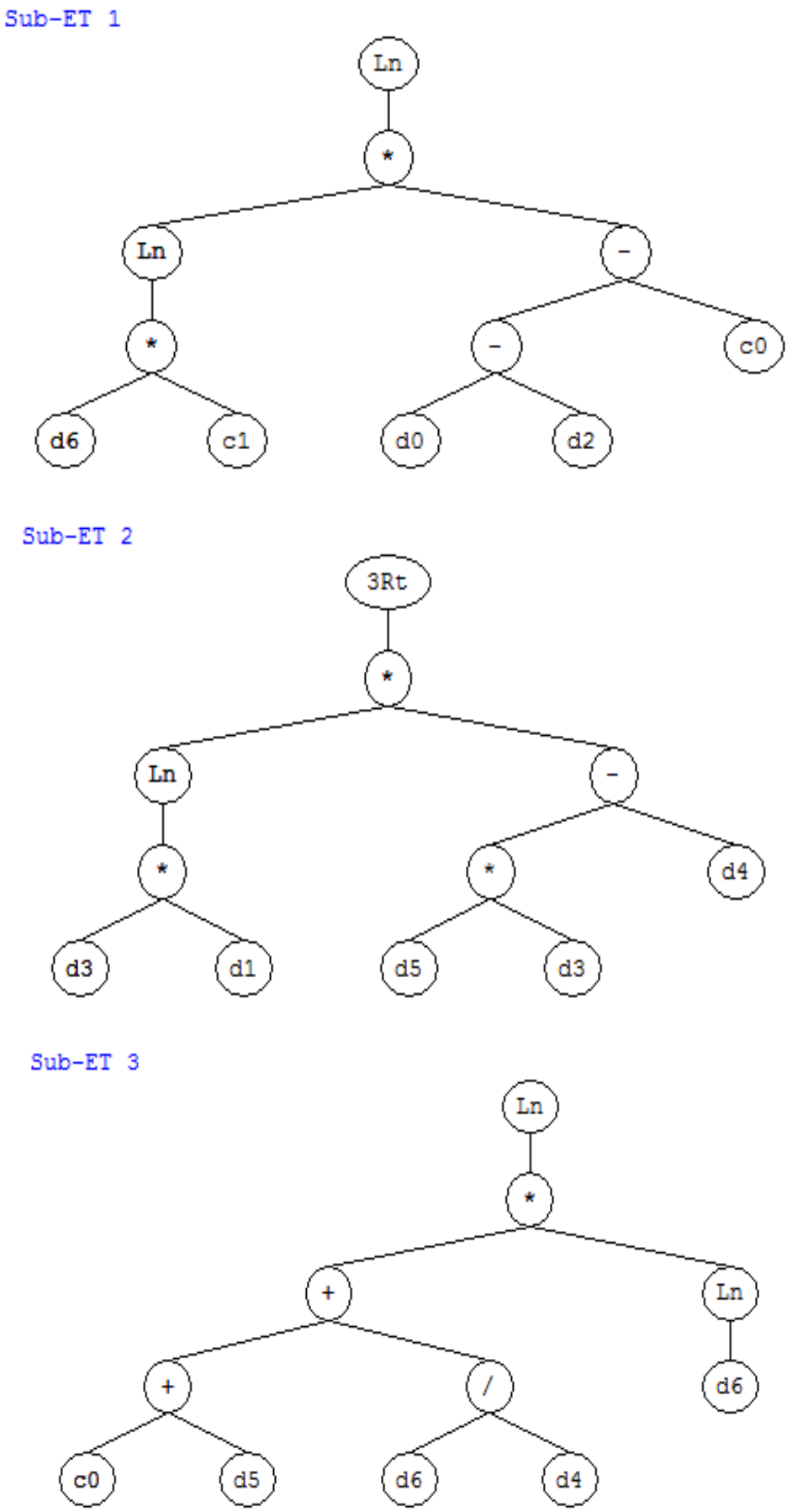

Fig. 2. Expression tree (ET) of the model; d0, d1, d2, d3, d4, d5 and d6 represents percentage of fly ash $(F)$, percentage of sand $(S)$, percentage of $\mathrm{Na}_{2} \mathrm{SiO}_{3}(N)$, curing temperature $(T)$, age of curing $(t), \mathrm{Na}_{2} \mathrm{SiO}_{3}$ to $\mathrm{NaOH}(\mathrm{KOH})$ weight ratio $(H)$ and liquid to ash weight ratio $(L)$. The exact value of $\mathrm{c} 0$ in sub-ET 1 is 8.843842 , c1 in sub-ET 1 is 3.579254, and c0 in sub-ET 3 is -8.576813 . 3Rt in Sub ET 2 means $\sqrt[3]{ }$. 


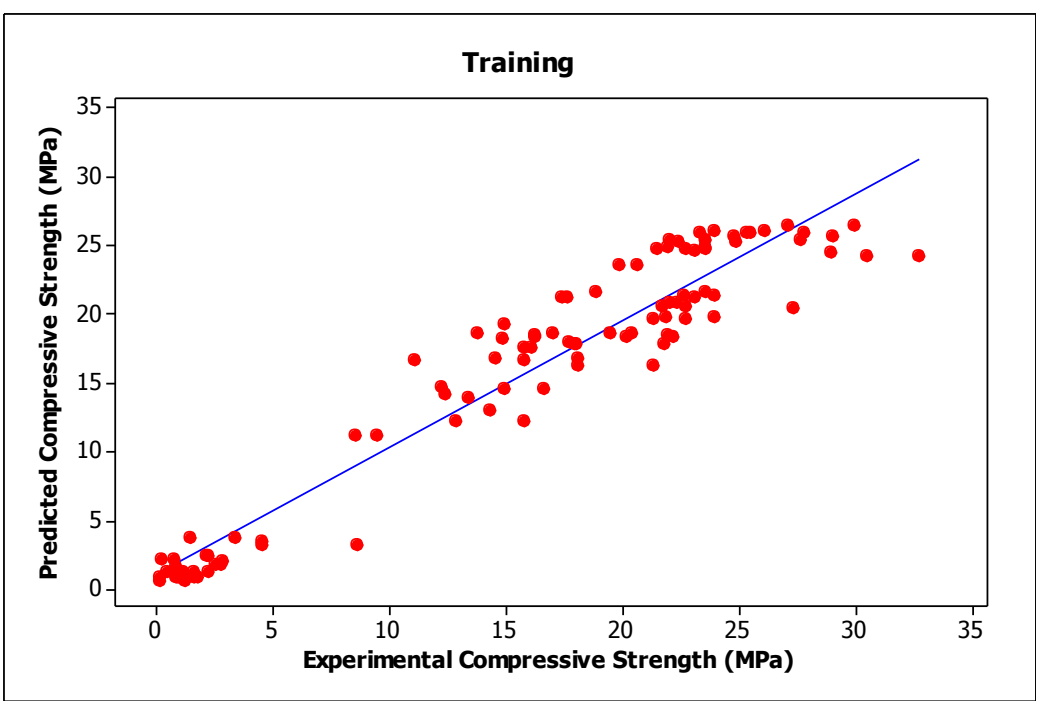

(a)

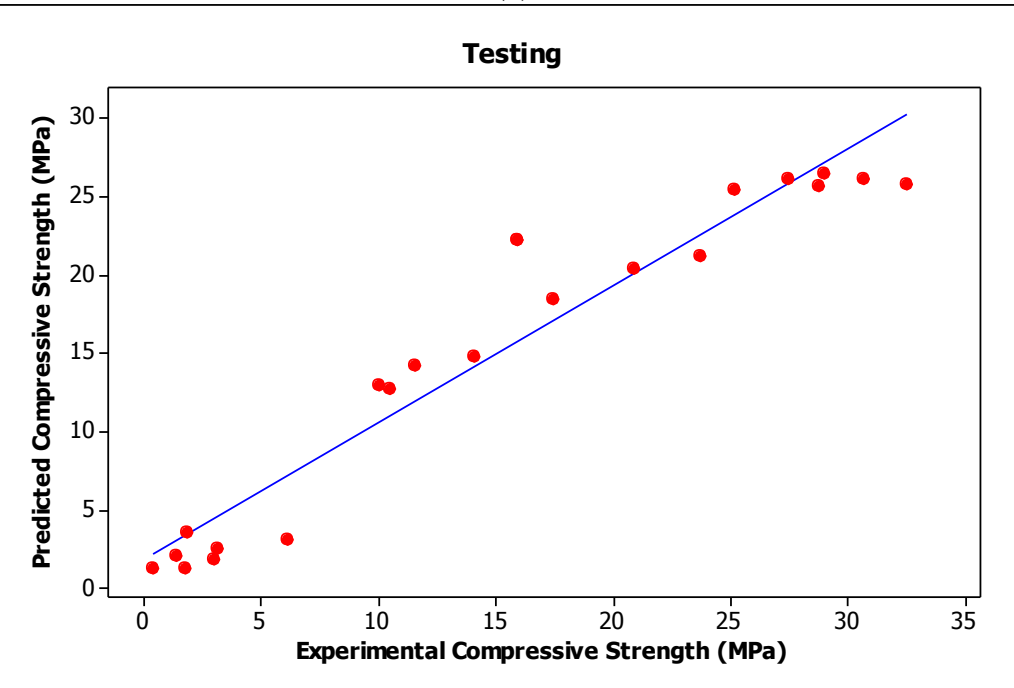

(b)

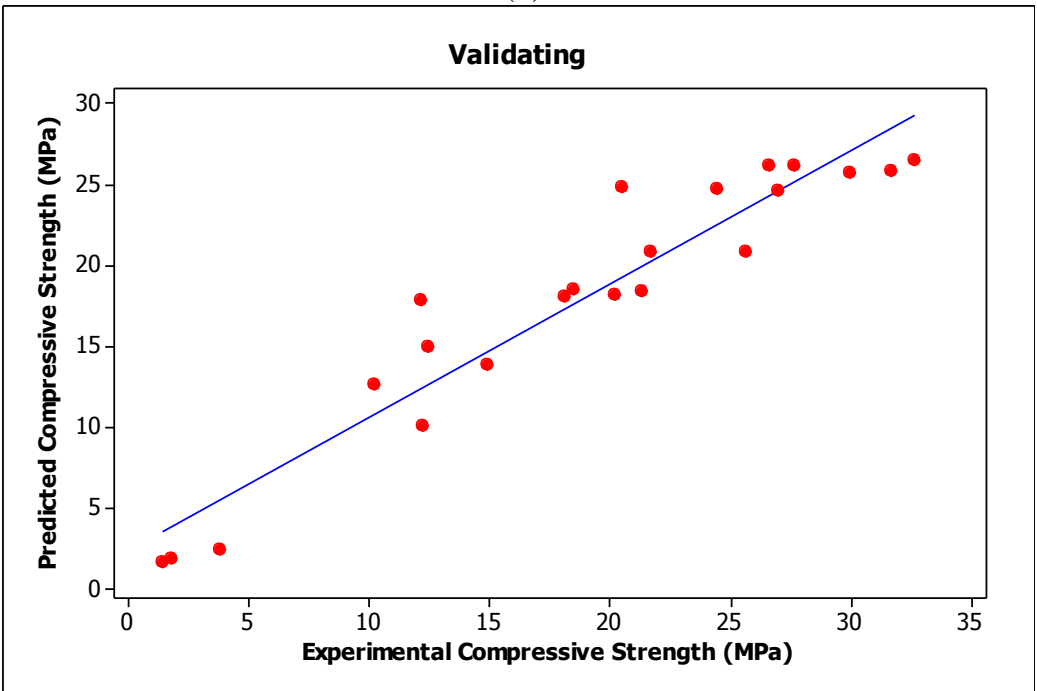

(c)

Fig. 3. Results of the model in a) training, b) validating and c) testing phases 


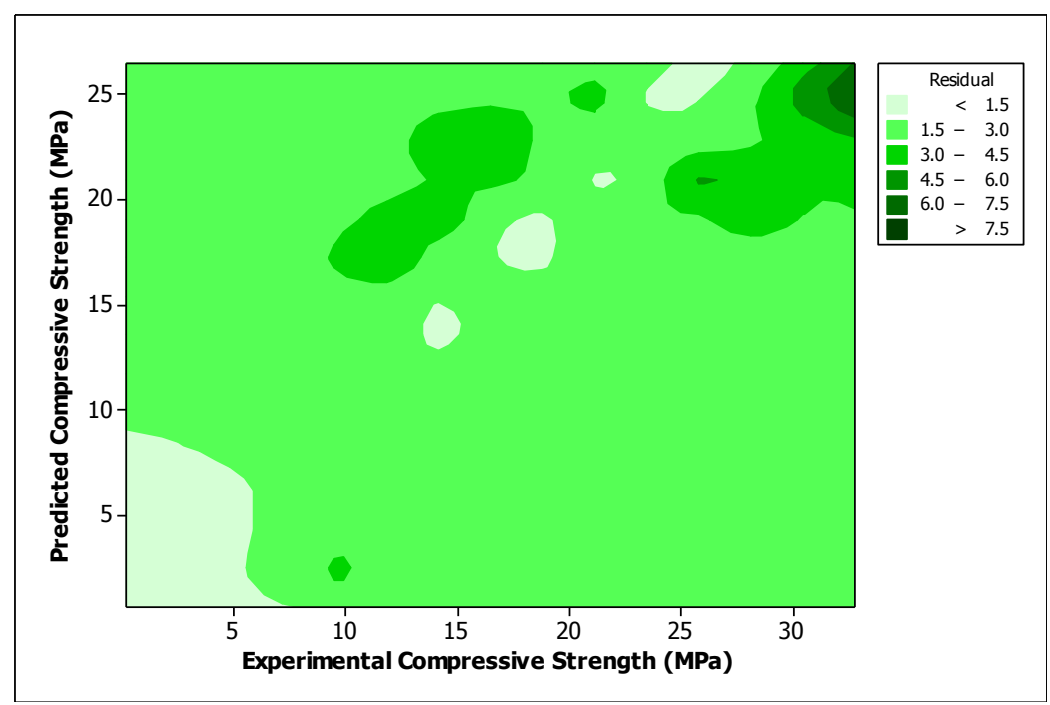

Fig. 4. Contour plot of residuals between experimental and predicted compressive strength

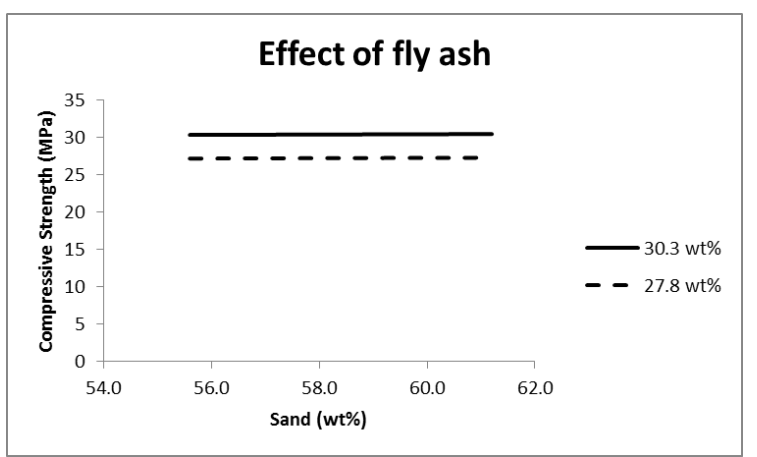

(a)

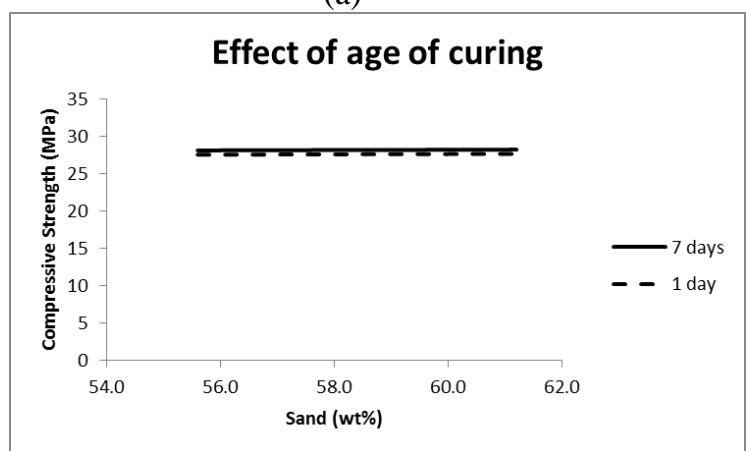

(c)

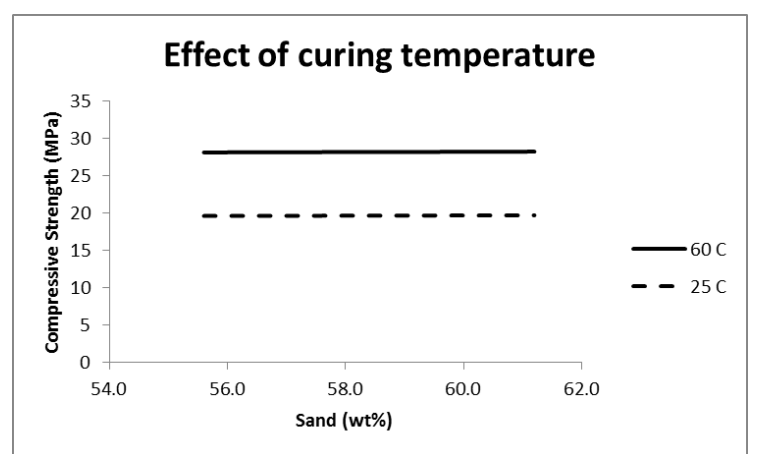

(b)

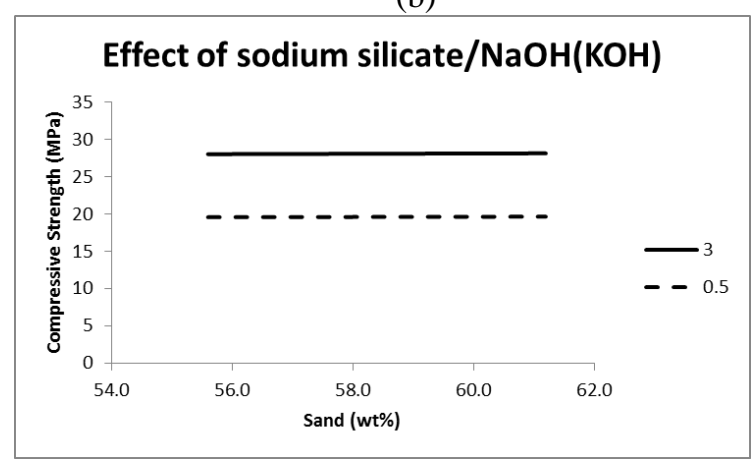

(d)

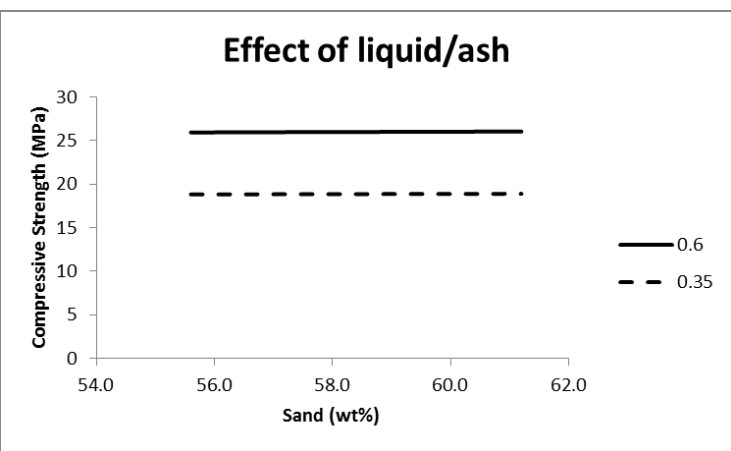

(e)

Fig. 5. The effect of percentage of sand on compressive strength of geopolymers 


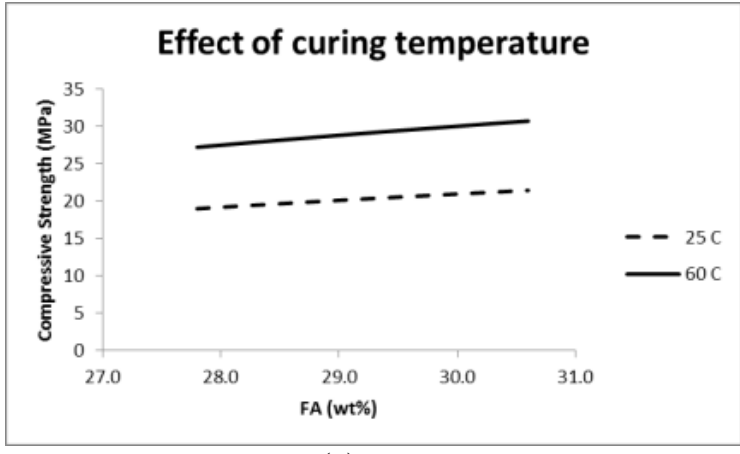

(a)

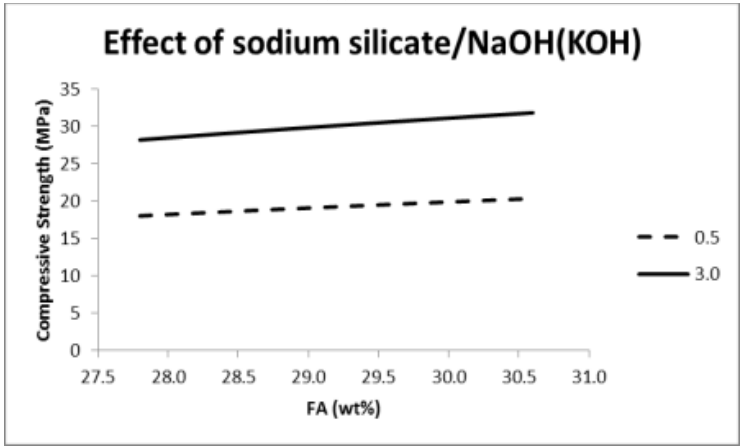

(c)

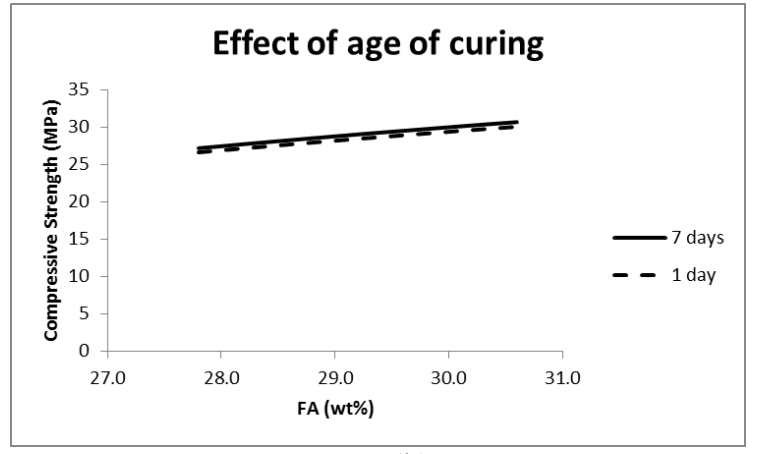

(b)

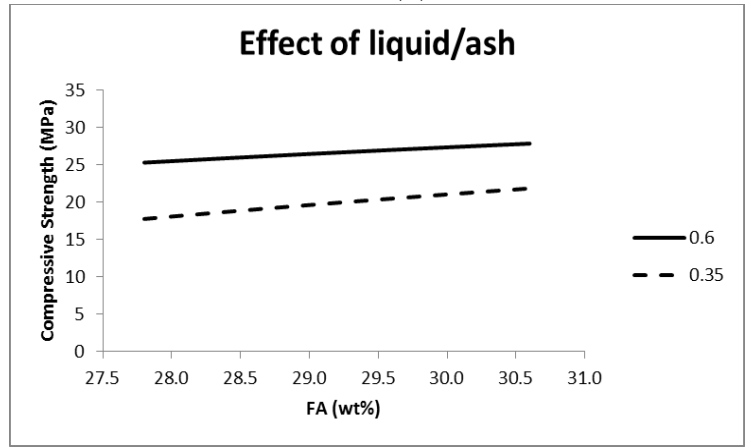

(d)

Fig. 6. The effect of percentage of fly ash on compressive strength of geopolymers 


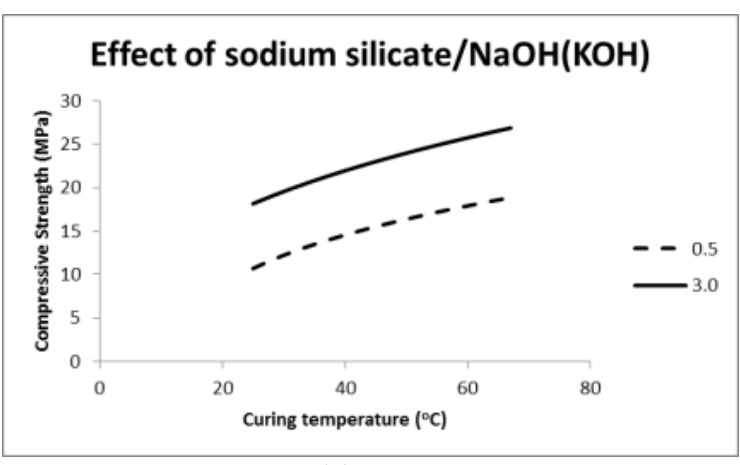

(a)

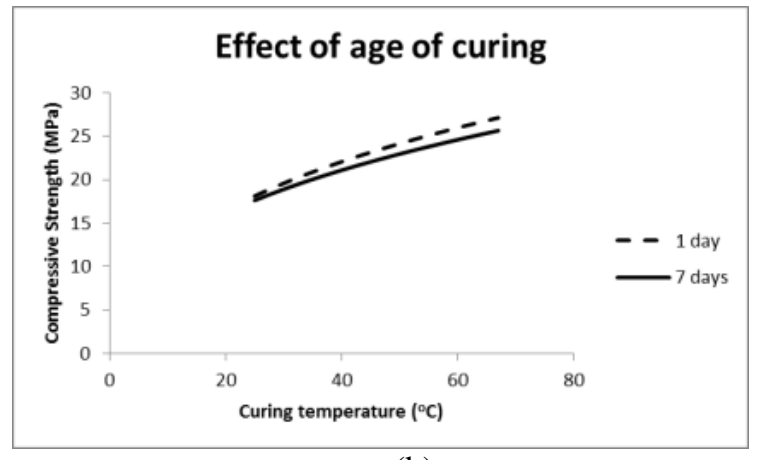

(b)

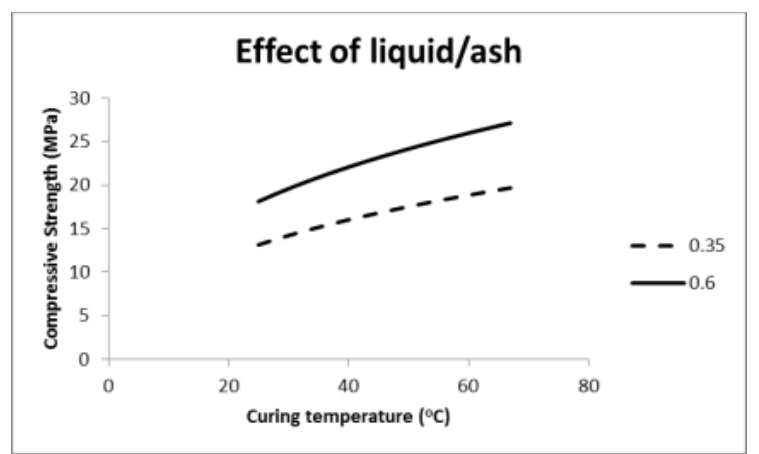

(c)

Fig. 7. The effect of curing temperature on compressive strength of geopolymers

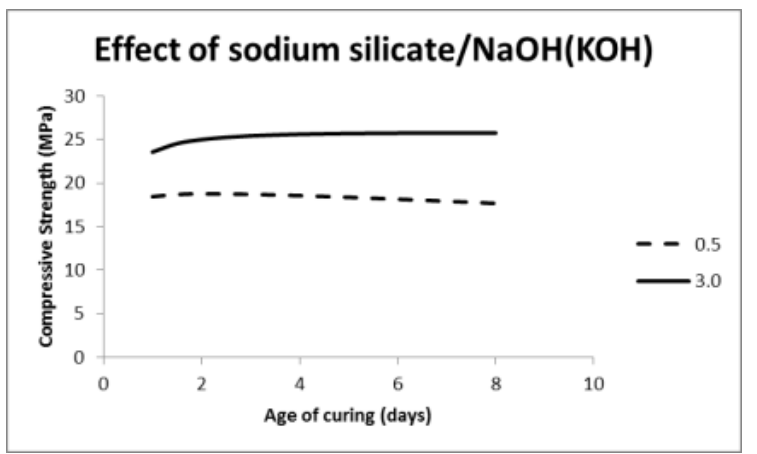

(a)

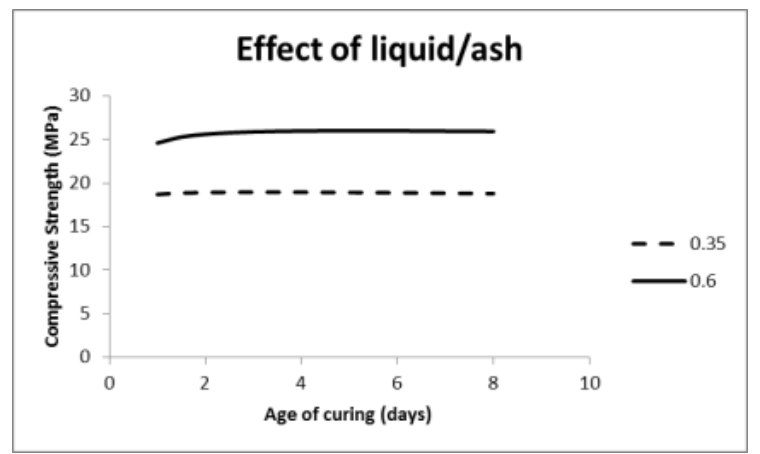

(b)

Fig. 8. The effect of age of curing on compressive strength of geopolymers

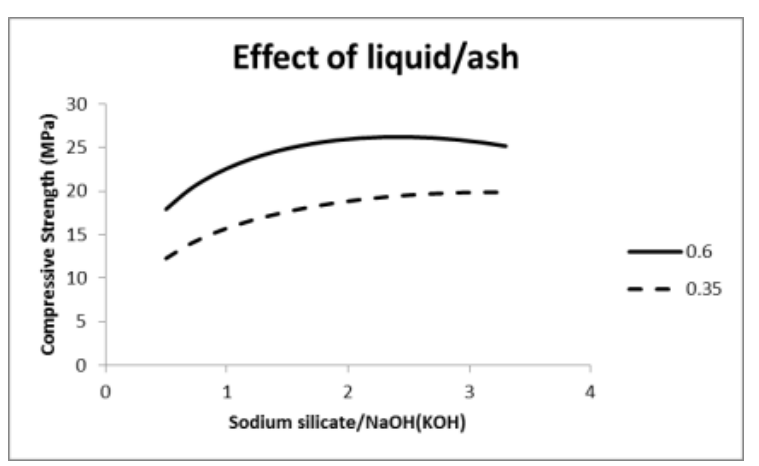

Fig. 9. The effect of sodium silicate/ $\mathrm{NaOH}(\mathrm{KOH})$ on compressive strength of geopolymers 